\section{Improvement of the accuracy of references in the Canadian Journal of Anaesthesia}

Migiwa Asano MD, Katsuya Mikawa MD,

Kahoru Nishina MD, Nobuhiro Maekawa MD, Hidefumi Obara MD

\begin{abstract}
A previous study indicated that there were many citation errors in the Canadian Journal of Anaesthesia. Afier this report, editors of the Journal requested any contributors, whose papers were accepted for publication, to verify the accuracy of reference citation by including a photocopy of the first page of each reference. The present study examined if the accuracy of the reference list had improved. We compared citation errors between volumes of 1990 and 1994. One hundred references from each year's publication were randomly selected. Afier citations of nonjournal articles were excluded, the remaining 190 citations were carefully scrutinized. Authors' names, article title, journal title, volume number, page numbers, and year were examined in each selected reference. $A$ reference was deemed correct if each element of the citation was identical to its source. Of the examined references, $48 \%$ and $22 \%$ contained one or more errors in 1990 and 1994, respectively. Errors in the title and author field of citation were most common in the either of the two years, occurring in about $70 \%$ of the references which contained some errors. Citation errors in Canadian Journal of Anaesthesia were considerably improved after the request to verify citation accuracy. Although this check-system probably contributes to the improvement of accuracy of reference citation, the rate of citation errors remains high. We believe that contributors' efforts will enhance the value of the journal.
\end{abstract}

Une étude antérieure a décelé, dans le Joumal Canadien d'Anesthésie, un grand nombre d'erreurs bibliographiques. Par la suite, les éditeurs ont demandé aux collaborateurs de la revue dont les articles étaient acceptés pour publication, de vérifier l'exactitude des références et de fournir une photocopie de la première page de chacune des celles-ci. Létude actuelle avait

\section{Key words}

ANAESTHESIA: journals;

PUBLICATION: documentation: Canadian Journal of Anaesthesia.

From the Department of Anaesthesiology, Kobe University School of Medicine, Kusunoki-cho 7, Chuo-ku, Kobe 650 Japan.

Address correspondence to: Dr. K. Mikawa.

Accepted for publication 12 December, 1994. pour but de vérifier s'il en avait résulté une plus grande exactitude pour les références. Nous avons comparé les erreurs bibliographiques entre les volumes 1990 et 1994. Cent références pour chacune des années de publication ont été sélectionnées au hasard. Après l'élimination de celles qui ne provenaient pas de revues, les 190 références résiduelles ont été examinées soigneusement. Le nom des auteurs, le titre de l'article, le titre du journal, le numéro du volume, les numéros de pages, et l'année ont été vérifiés dans cet ordre. Une référence était jugée correcte si chacun des ses éléments était identique à sa source. Des références étudiées, $48 \%$ et $22 \%$ contenaient respectivement une erreur ou plus en 1990 et en 1994. Les erreurs de titres et d'auteurs étaient les plus fréquentes pour chacune des deux années et survenaient dans $70 \%$ des cas de références erronées. Les erreurs bibliographiques ont considérablement diminué dans le Journal Canadien d'Anesthésie après cette demande de vérification. Bien que ce système aide à améliorer la fidélité des références, le taux d'erreurs demeure élevé. Nous croyons que les efforts de la part des collaborateurs du Journal continueront d'améliorer son calibre.

Accurate references assist the reader who wants to learn about a new field. Such a reader uses the reference list of manuscripts to approach the background literature for a study already determined to be interesting. Nothing is more frustrating than to cover unidentifiable references. Bibliographies prepared with care prevent this frustration. Thus, reference accuracy is essential to a scientific paper. A report published in 1992 indicated that four anaesthesia journals with established reputations had many citation errors in the reference lists.' These included Canadian Journal of Anaesthesia, Anesthesiology, Anesthesia and Analgesia, and British Journal of Anaesthesia.

At present, in the letter requiring a revised version of manuscript, the Canadian Journal of Anaesthesia requests contributors to verify accuracy of references and to submit photocopies of the first page of each of the references quoted. It was felt worthwhile to conduct the present study to examine if the accuracy in the reference list of the journal had been improved since the editor's request. To make this assessment, we compared citation 
TABLE I Number of errors per citation. Major errors are shown in parentheses.

\begin{tabular}{llllll}
\hline \multirow{2}{*}{$\begin{array}{l}\text { Number of errors } \\
\text { per citation }\end{array}$} & \multicolumn{2}{l}{1990 (issue no. 1-8) } & & \multicolumn{2}{l}{1994 (issue no. 1-6) } \\
\cline { 2 - 3 } & Frequency Percent & & Frequency Percent \\
\hline 0 & 49 & 52.1 & & $75^{*}$ & 78.1 \\
1 & $34(4)$ & $36.2(4.2)$ & & $19(3)$ & $19.8(3.1)$ \\
2 or more & $\frac{11(1)}{11.7(1.1)}$ & $\frac{21(0)}{20}$ & $\frac{2.1(0)}{100(3.1)}$ \\
Total & $94(5)$ & $100(5.3)$ & & $96(3)$ & $100(3.1)$ \\
\hline
\end{tabular}

${ }^{*} P<0.05$, significantly larger than in 1990 .

$\dagger P<0.05$, significantly smaller than in 1990

errors between 1990 and 1994 volumes. Any contributor, whose paper was published in 1994, was considered to have been requested to check citation accuracy. No other major changes of editorial policy were implemented in these four years.

\section{Methods}

All 1990 issues of Canadian Journal of Anaesthesia (from January to November) were examined. Beginning with the first reference in the January issue and ending with the last reference in the November issue, every citation was numbered sequentially $(n=3701)$. Using a table of random numbers, we chose 100 references. References to non-journal items, such as books and book chapters, were excluded from the analysis, leaving a total of 94 references for minute scrutiny.

A reference form was prepared; this helped to identify any citation by its sequential number and the journal in which it appeared. Data fields for the cited reference corresponded to six standard elements of bibliographic citation: authors (including correct number, order, initials, and spelling), article title, journal title (including proper Index Medicus abbreviation), volume number, page number, and year.

Citations were then verified by comparison with the original publication (primary source). If our institution did not own the source, we attempted to procure a copy thereof through interlibrary loan.

Citations containing no errors were classified as correct; if an error existed in any element, the citation was classified as incorrect. Punctuation errors were included. Errors which potentially impede retrieval of the original paper are regarded as major: (1) errors which are completely different from original (not typographic error), and (2) typographic errors of "volume," "year," and "page (the first page of a reference)" fields. In contrast, punctuation errors and typographic errors of other fields (author, title, journal, and the last page of reference) are regarded as minor. These errors probably do not prevent readers from retrieving original manuscripts.
TABLE II Distribution of errors among each of the six chosen bibliographic parameters. Major errors are shown in parentheses

\begin{tabular}{lccccc}
\hline \multirow{2}{*}{$\begin{array}{l}\text { Bibliographic } \\
\text { element }\end{array}$} & \multicolumn{2}{l}{1990 (issue no. 1-8) } & & \multicolumn{2}{l}{1994 (issue no. 1-6) } \\
\cline { 2 - 3 } \cline { 6 - 6 } \cline { 5 - 6 } & Frequency & Percent & & Frequency & Percent \\
\hline Title & $31(0)$ & $49.2(0)$ & & $7(0)$ & $29.2(0)$ \\
Author & $16(0)$ & $25.4(0)$ & & $10(0)$ & $41.7(0)$ \\
Page & $12(4)$ & $19.0(6.3)$ & $5(2)$ & $20.8(8.3)$ \\
Journal & $2(0)$ & $3.2(0)$ & & $1(0)$ & $4.2(0)$ \\
Volume & $2(2)$ & $3.2(3.2)$ & $1(1)$ & $4.2(4.2)$ \\
Year & $0(0)$ & $0(0)$ & & $0(0)$ & $0(0)$ \\
Total & $63(6)$ & $100(9.5)$ & $24(3)$ & $100(12.5)$ \\
\hline
\end{tabular}

$P>0.05$ in distribution of errors between 1900 and 1994.

In like manner, we identified 100 references from 1994 issues (from January to June, $n=2000$ ) of the journal, and analysed 96 references with the exception of four references which pertained to nonjournal items.

Data are presented as frequency or percent, overall and by element for each year (1990 and 1994). Differenes in frequency and percent of errors between 1990 and 1994 were tested for statistical significance using the chisquare test. The Fisher's exact test with an $r \times c$ contingency table was used when data did not conform with assumptions underlying the chi-square method were not met. $P<0.05$ was deemed significant.

\section{Results}

Consistent with the previous report examining 1988 issues of the journal, many references contained an error (48\%) in at least one element of citation in 1990 (Table I). In 1994 , the rate of citation errors decreased to $22 \%$. The number of multiple errors also decreased to $2 \%$. In 1990 , five references had major errors, while three had major errors in 1994. We retrieved these original references with difficulty. Two of them (one reference each year) were procured by computer retrieval.

Table II indicates that errors in the title field of citation were most common in 1990, occurring in about $50 \%$ of the references which contained some errors. Author errors were the second most common. In contrast, although title errors decreased, error rates in the author field remained high in 1994. Errors of journal and volume were less frequent. No year error was found in the two years. There was no difference in the rate of major errors.

\section{Discussion}

Accurate reference lists provide readers with useful information about their studies. We believe that correct citation of references improves the quality of the journal. Although contributors to any journal have the responsibility to cite references accurately, many fail to do so. 
In 1992, McLellan et al. called the attention of authors and readers in the field of anaesthesia to inaccuracy of the reference lists observed even in the esteemed journals. ${ }^{1}$ They examined 1988 volumes of each journal. After their report, editors of Canadian Journal of Anaesthesia began to ask contributors to verify citation accuracy and submit photocopies of the first page of each of the reference quoted, when the contributors were requested to revise their manuscript. In the present study, we have confirmed that Canadian Journal of Anaesthesia formerly had many citation errors in the reference list. Furthermore, we have shown that citation errors in 1994 decreased by more than $50 \%$ compared with in 1990 . However, no difference in the rate of major errors was found between the two years. Since major errors are clearly less common than minor errors, a sample size of only 100 references in each year in the present study may have been inadequate for drawing a valid statistical inference on the status quo of the problem. We conducted a similar study on Anesthesia and Analgesia and British Journal of Anaesthesia. In these journals which did not change editorial policy after McLellan's report, the rates of citation errors did not decrease (from $36 \%$ to $38 \%$ in "Anesth Analg" and from $47 \%$ to $36 \%$ in "Br J Anaesth", $P>0.05$ ). Thus, this improvement of citation accuracy in Canadian Journal of Anaesthesia is due probably to the reference checksystem by editors and contributors. We believe that the decrease in citation errors has made the journal more useful and reliable, leading to improved quality. However, since the rate of citation errors remains at $22 \%$, further contributors' efforts are needed to verify the accuracy of the reference lists before submission of their manuscripts. Contributors should check the accuracy especially of the author field in the reference lists thoroughly. Citation errors in this field do not seem to have decreased in the four years. Furthermore, since this improvement may reflect on bias of temporal change, studies are required to periodically examine the error rate.

In conclusion, we have shown that citation errors in Canadian Joumal of Anaesthesia have decreased. We expect contributors to make further efforts so as to enhance the value of the journal.

\section{Reference}

1 McLellan $M F$, Case $L D$, Barnett MC. Trust, but verify: the accuracy of references in four anesthesia journals. Anesthesiology 1992; 77: 185-8. 